\title{
O "Boletim da Clínica Psiquiátrica da FMUSP", 1962-1971: publicação esquecida, retrato de uma época
}

\author{
The "Boletim da Clínica Psiquiátrica da FMUPS," 1962-1971: \\ a forgotten publication and portrait of an era
}

\author{
Gustavo Gil Alarcão ${ }^{i}$ \\ i Pesquisador colaborador, Instituto \\ de Psiquiatria/Faculdade de \\ Medicina/Universidade de São \\ Paulo. \\ São Paulo - SP - Brasil \\ orcid.org/0000-0002-7647-5323 \\ gustavogilalarcao@yahoo.com.br
}

\section{André Mota ${ }^{i i}$ \\ ii Professor, Departamento de Medicina Preventiva/Faculdade de Medicina/Universidade de São Paulo. \\ São Paulo - SP - Brasil orcid.org/0000-0002-5697-8628 andremota13@gmail.com}

Recebido em 17 jan. 2020.

Aprovado em 30 out. 2020.
ALARCÃO, Gustavo Gil; MOTA, André. O “Boletim da Clínica Psiquiátrica da FMUSP", 1962-1971: publicação esquecida, retrato de uma época. História, Ciências, Saúde - Manguinhos, Rio de Janeiro, v.28, n.3, jul.-set. 2021, p.849-861.

Resumo

O artigo retrata a história inédita do Boletim da Clínica Psiquiátrica da Faculdade de Medicina da Universidade de São Paulo, publicado entre 1962 e 1971. Trata-se da primeira publicação científica da Clínica Psiquiátrica, substituída pela Revista de Psiquiatria Clínica, existente até os dias de hoje. O Boletim é uma valiosa fonte de pesquisa histórica, que retrata uma década da psiquiatria brasileira. Seu conteúdo é composto por trabalhos variados: testes de medicação, discussões teóricas, notícias da época e questões institucionais da formação da psiquiatria e de áreas correlatas como a psicologia e a psicanálise. A chegada das medicações, a busca pela padronização dos diagnósticos e textos ensaísticos são parte desse conteúdo.

Palavras-chave: história da psiquiatria; história da psicoterapia; Instituto de Psiquiatria/FMUSP; Antônio Carlos Pacheco e Silva (1898-1988); psiquiatria em São Paulo.

\section{Abstract}

This article describes the Boletim da Clínica Psiquiátrica da Faculdade de Medicina da Universidade de São Paulo, which was published from 1962 to 1971. This was the first scientific publication of the Psychiatric Clinic, and was replaced by the Revista de Psiquiatria Clínica, which still exists today. The Boletim is a valuable source for historical research, spanning a decade of Brazilian psychiatry, and contains a variety of content: medication trials, theoretical discussions, current events, and institutional issues related to the development of psychiatry and related areas such as psychology and psychoanalysis, as well as the arrival of medications and the search for standardized diagnoses.

Keywords: history of psychiatry; history of psychotherapy; Instituto de Psiquiatria/FMUSP; Antonio Carlos Pacheco e Silva (1898-1988); psychiatry in São Paulo. 
$\mathrm{O}$ Boletim Bibliográfico da Clínica Psiquiátrica da Faculdade de Medicina da Universidade de São Paulo (FMUSP) criado em 1962, foi inicialmente destinado à publicação de resenhas de livros ou revistas do campo psi feitas por psiquiatras da própria instituição. Logo em seu terceiro número adquiriu novo status, tornando-se o Boletim da Clínica Psiquiátrica. Seu conteúdo foi ampliado e diversificado, sendo formado por artigos originais, conferências, aulas e notícias da época, o que o tornou uma publicação de referência para seu tempo (Amaro, 2003).
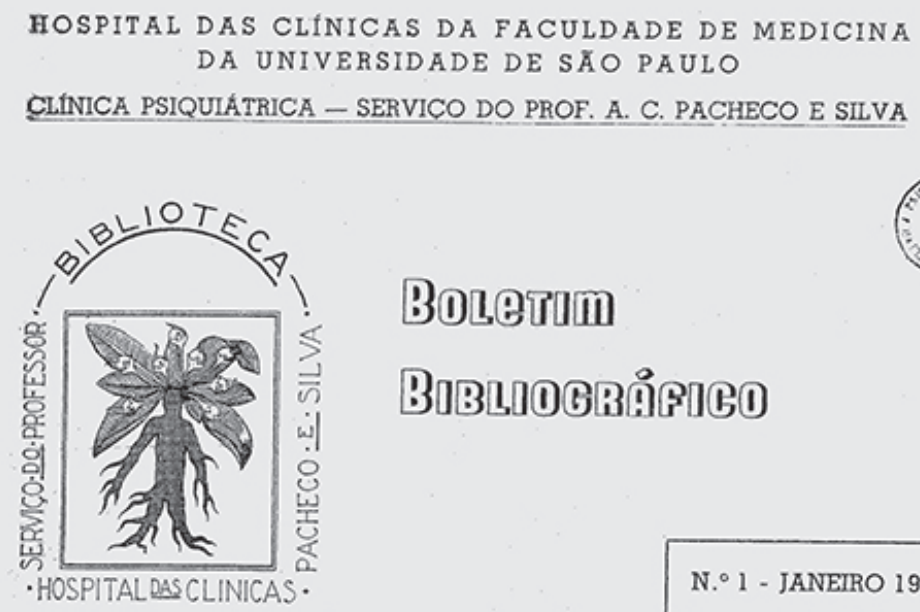

\section{BDLอบดm}

\section{ВВLIOBВด̊PIค๐}

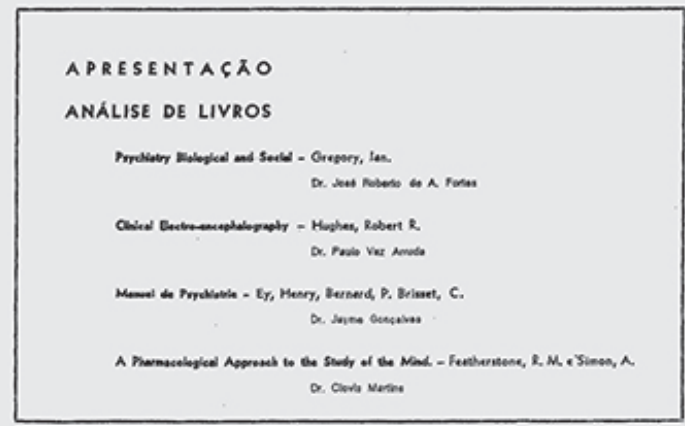

Esizado pels BIBLIOTECA DO SERVICOO DO PROF. A. C. PACHECO E SILVA, sob responsobilidade do Dr. Clovis Martins - Secretária: Morgarida Frusso - Cx. Postal anor Cr. D... "..

Figura 1: Capa do primeiro número do Boletim Bibliográfico, de 1962 (Boletim Bibliográfico FMUSP, n.1, 1962) 
O Boletim ficou sob responsabilidade de Clóvis Martins ${ }^{1}$ (1920-2011), seu único diretor. Antônio Carlos Pacheco e Silva (1898-1988), grande nome da psiquiatria brasileira associado ao organicismo, dirigiu a psiquiatria da FMUSP entre 1936-1968, sendo substituído por um de seus principais assistentes, Fernando de Oliveira Bastos, em 1968 (Bastos, 1968), ano de modificações na estrutura universitária do país, que criava cargos de professores titulares em substituição aos catedráticos da época (Fávero, 2006).

O exame do Boletim teve como objetivo obter informações acerca de ideias e práticas em vigência na Clínica Psiquiátrica da FMUSP (Bourdieu, 2011; Gama, 2012). Percorremos todo o seu conteúdo, disponível na biblioteca do atual Instituto de Psiquiatria da FMUSP. Nosso interesse é o de retratar com fidedignidade a década representada pelo Boletim, para que o leitor possa observar as mudanças e as permanências da psiquiatria, objetivo que pode ser realizado ao tomar o Boletim como fonte histórica (Mota, 2012). A partir disso, podemos entender a psiquiatria como racionalidade científica subordinada ao contexto sociocultural de seu lugar e tempo (Fonseca, 2002; Costa, 2006), influenciando e sendo influenciada pelos agentes envolvidos com seus processos históricos de saber e prática (Facchinetti, Cupelo, Evangelista, 2010).

\section{A organização do Boletim}

Foram publicados 47 números do Boletim, bimestralmente em 1962 e 1963, e trimestralmente entre 1964 e 1971 (em 1967 e 1968 publicaram-se também três suplementos). Não havia uma definição constante das categorias de cada edição, bem como do número de textos. As categorias e as quantidades de artigos publicados foram: 75 análises de livros, 71 conferências e aulas, sessenta trabalhos originais, 11 registros de casos, quatro análises de revistas e quatro transcrições de textos. Contabilizam-se 123 autores, dos quais se destacam, pelo número de publicações, Clóvis Martins, Públio Salles Silva (professor-assistente), Antônio Carlos Pacheco e Silva, Fernando de Oliveira Bastos e Jorge W.F. Amaro (psiquiatra e psicanalista, fundador do Serviço de Psicoterapia na Clínica Psiquiátrica).

A publicação era financiada pelos psiquiatras do hospital e por doações de particulares ou empresas, principalmente farmacêuticas. Todos os números apresentavam ao final um movimento de caixa em que se indicavam recebimentos e gastos. As contribuições eram escalonadas de acordo com a hierarquia institucional, cabendo aos mais graduados parcelas maiores. Contribuíam: professor catedrático, professores-assistentes, médicos contratados, médicos auxiliares, médicos estagiários, demais profissionais e estagiários e estudantes. Para efeitos de comparação, em maio de 1962, Pacheco e Silva contribuiu com cinco mil cruzeiros, enquanto estudantes contribuíram com trezentos cruzeiros e as doações somavam 13.356 cruzeiros da empresa Chimica Bay e quatro mil cruzeiros do senhor Waldomiro Marcondes (Martins, 1962a, p.16).

A partir de seu segundo número observa-se a presença de propagandas, cada vez mais comuns e que se tornaram parte da receita do Boletim. Encontramos como patrocinadores: Procienx (um laboratório da época), Johnson \& Johnson (presente em todos os anos), Rodhia e Pfizer: 
Problemas surgidos faz tempo agora tomam vulto; o mais antigo e duradouro é o do papel, cujo consumo recente ultrapassou as disponibilidades do almoxarifado do Hospital das Clínicas. Conseguimos com a Cia. Rodhia do Brasil 45 mil folhas do papel próprio, metade do que ainda necessita o Boletim para o resto de seu segundo volume de 1963. Por isso ele passará a ser mimeografado nos dois lados da folha. Façamos uma pausa para registrar novos e sinceros agradecimentos a essas indústrias farmacêuticas: Johnson \& Johnson, Rodhia e Procienx pela presteza e compreensão com que sempre nos ajudam. Surgiu um novo obstáculo, o protocolo geral do HC não tem recursos materiais para proceder à distribuição postal do Boletim da maneira habitual (Martins, 1963a, p.44).

Outro excerto indica que as "dificuldades materiais paralelas ao crescimento da publicação levaram-nos a aceitar a publicidade de produtos farmacêuticos, a ser inserida fora do texto. Colocada rigorosamente dentro de padrões éticos e científicos e conformada ao tipo gráfico da publicação, terá a vantagem de emprestar à revista certo caráter decorativo" (Martins, 1963b, p.100).

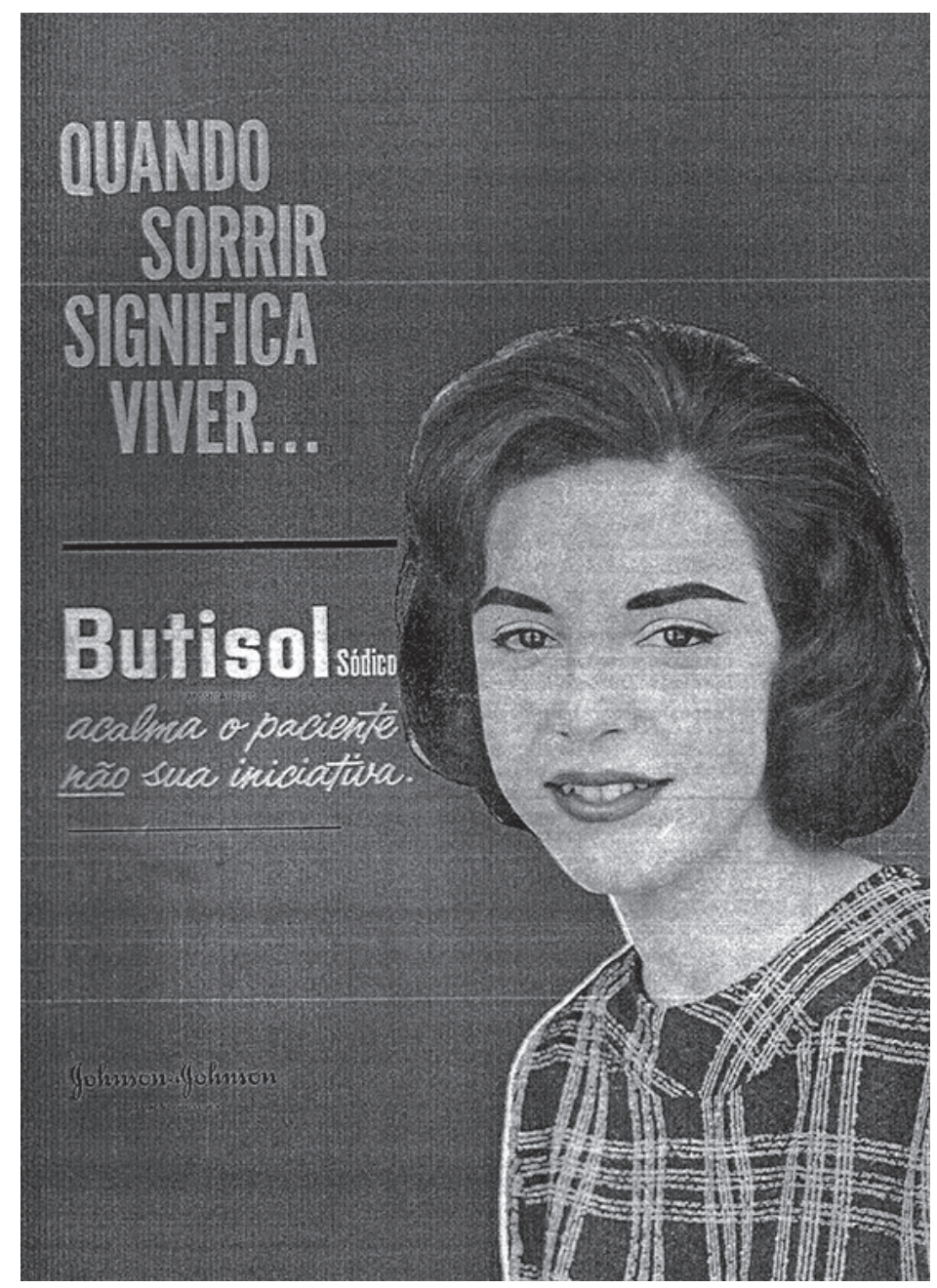

Figura 2: Propaganda da indústria farmacêutica (Boletim Bibliográfico FMUSP, v.3, n.1, p.10, 1964) 
A tiragem de trezentos exemplares manteve-se permanente durante o período, com eventuais dificuldades na postagem, como indicado na nota acima. Em seu número de lançamento consta modesta apresentação: “A Biblioteca procurará apresentar tão regularmente quanto possível, um pequeno boletim contendo a apreciação crítica dos últimos livros adquiridos ou a análise de trabalhos publicados nas revistas por nós recebidas. Os que se interessarem em colaborar nessa tarefa procurem-nos com suas sugestões e para a escolha de publicação a ser analisada (Martins, 1962b, p.1)". Mas, já em seu segundo ano e como Boletim passa a alçar ambições maiores:

Com este número inicia-se, tecnicamente, nova fase da vida (ainda curta) do nosso Boletim. Antes de atingir maioridade ou, quem sabe, por já tê-la atingido muito depressa, precisou mudar de nome: os dois primeiros números eram realmente bibliográficos, do terceiro em diante, porém deixou de sê-lo, senso strictu, e agora a boa vontade dos leitores já poderá distinguir nele as feições de uma revista especializada. Por isto mesmo algumas das bibliotecas para onde está sendo enviado, manifestaram dificuldade em indexá-lo pelo título. Estes os motivos da mudança; passa então, desde hoje, a chamar-se Boletim da Clínica Psiquiátrica, nome de pureza espartana que, se não choca pela originalidade, também não promete ambições desmedidas, antes revela salutar e equilibrado sentido de medida (Martins, 1963a, p.2).

A cada novo número, os editais informavam o sucesso da publicação, a ampliação de sua distribuição e de seu escopo, enaltecendo a construção de sua própria história.

\section{O conteúdo}

O Boletim foi um importante veículo de consolidação da psiquiatria. Em 1936, a psiquiatria da FMUSP desmembrou-se da neurologia, adquirindo status de disciplina independente (Alarcão, Mota, 2019). Fato importante para os rumos da psiquiatria, já que o vencedor do primeiro concurso para professor catedrático de psiquiatria, Pacheco e Silva, impedido por lei de acumular cargos públicos, foi obrigado a optar pela Faculdade de Medicina em detrimento da chefia da Assistência aos Alienados do Estado de São Paulo. Assim, tratou de mobilizar sua influência política para construção de uma clínica psiquiátrica anexa ao Complexo Hospitalar do Hospital das Clínicas, que seria inaugurada apenas em 1954 (Alarcão, 2018).

Durante esse período, a psiquiatria paulista buscava consolidar-se como um campo independente dentro da medicina, afirmando-se, repetidamente, científica e médica. Dizerse científica ou médica significava acima de tudo, dizer-se "não teórica", "não filosófica" e "não especulativa" (Costa, 2004). Portanto, não foi um acaso que o primeiro escrito que não analisava bibliografia, em 1962, foi a conferência de Pacheco e Silva "A pesquisa científica, métodos experimentais, filosofia da experimentação". Esse conteúdo repete-se em "Evolução da psiquiatria" (1962), "As grandes linhas de um humanismo científico" (1964), "A atividade mental do pesquisador" (1965) e "A moderna assistência psiquiátrica" (1967).

Também em 1962, o Boletim informava a inauguração do Centro de Neurocirurgia Funcional da Clínica Psiquiátrica. Públio Salles Silva (1962, p.28) escreveu que era de suma importância para a psiquiatria não "enveredar pelos domínios da filosofia ou da metafísica 
psiquiátrica". Públio recoloca a psiquiatria ao lado da neurologia, caracterizando o Centro como "um dos mais sólidos marcos da neuropsiquiatria moderna" (p.29).

No artigo de Pacheco e Silva (1970) "Sobre a necessidade da criação de um hospital psiquiátrico municipal na cidade de SP", ratificava-se a posição da psiquiatria científica e médica na cidade. A defesa de um sistema concêntrico de hospitais com feições de hospitais comuns, tentando se diferenciar dos antigos manicômios, ilustrava a presença do psiquiatra médico e do hospital na cidade, e não mais na periferia. Essa psiquiatria ainda exibia suas contradições, defendendo tratamentos humanizados, mas preservando ideias higienistas:

Quando um grupo social se vê ameaçado de desorganização e desintegração, impõe-se a identificação das causas responsáveis, para depois eliminá-las com base na medicina, na higiene. No sentido de se proceder a chamada limpeza orgânica de uma cidade, para escoimá-la dos elementos nocivos, a primeira providência consiste em retirar de circulação todos aqueles que perturbem a vida social e revelem falta de adaptação, submetendo-os a rigorosa triagem, para, a seguir, encaminhá-los aos diferentes lugares, conforme o resultado dos diagnósticos, dos exames e das observações procedidas (Silva, 1970, p.19).

\section{A tentativa de padronização da clínica e dos diagnósticos}

O paradigma dos diagnósticos psiquiátricos não seria alterado na década de 1960, mas somente a partir de 1980, com a chegada do terceiro manual diagnóstico norte-americano, o DSM III (Russo, Venâncio, 2006; Figueiredo, Tenório, 2002). Durante os anos do Boletim acompanhamos precisamente uma década de transição, em que se observam tentativas de padronização da clínica e dos diagnósticos, ainda sem presença da estatística e da epidemiologia, que viriam a dominar o campo (Luz et al., 2007). Lemos no artigo de Pacheco e Silva "Contribuição ao estudo de uma classificação das doenças mentais" (Silva, 1962, p.9) que:

No meu entender, uma classificação em psiquiatria é um fio condutor absolutamente necessário, muito embora não seja possível, no estado atual dos nossos conhecimentos, estabelecer-se uma classificação rigorosa das doenças mentais. Daí a razão por que muitos autores julgam ser preferível empregar-se, por enquanto, a expressão nomenclatura psiquiátrica. Na realidade todas as classificações até hoje propostas, e se contam por dezenas, são ecléticas, em virtude da impossibilidade de se adotar, na sua evolução, um critério único, seja etiológico, sintomatológico, anatomopatológico ou evolutivo, na divisão dos vários quadros nosográficos de que se compõe a psiquiatria, muitos dos quais não constituem ainda entidades clínicas perfeitamente definidas e demarcadas.

A psiquiatria, que durante os anos precedentes se utilizava do referencial psicanalítico para elaborar seus diagnósticos, rumava para outra direção. Como mostra Zaretsky (2006), tal processo acompanhou um período de desinteresse pela psicanálise, iniciado principalmente nos EUA e que marcaria profundamente a relação futura entre psiquiatria e psicanálise. Mas Zaretsky também informa que o DSM II ainda era, em grande medida, psicanalítico, o que coincide com o que se encontra nas publicações do Boletim, em que textos psiquiátricos que buscam homogeneizar diagnósticos compartilham espaço com 
textos sobre psicologia e psicanálise. Em 1970, a Classificação Internacional de Doenças (CID) da Organização Mundial de Saúde (OMS) é publicada ainda com vários diagnósticos influenciados pela psicanálise: estados paranoides, neurose de angústia, neurose histérica, neurose fóbica, neurose obsessiva e neurastenia (Dunker, 2014; Martins, 1970) e foi noticiada pelo Boletim.

Em paralelo, observamos que a publicação de casos clínicos no Boletim mostravam uma padronização de forma, nomenclatura, procedimentos diagnósticos e condutas terapêuticas. O texto de Públio Salles Silva "Um caso de hipercalculia" (1963) é um claro exemplo. O psiquiatra médico passará a apresentar seus casos de forma "médica", buscando parâmetros objetivos, medidas, resultados de teste e exames (Machado et al., 1978), o que se constata nos artigos "Enurese" (1967) de Sandra Gouveia, e "Síndrome temporal" (1971) de Sidney Chioro.

\section{A chegada dos remédios}

Um grande ponto do Boletim é noticiar os experimentos com as novas medicações psicotrópicas:

Ultimamente, iniciamos a experimentação clínica da trifluoperazina no tratamento das doenças mentais e, nesta publicação, vamos relacionar os resultados que obtivemos e as conclusões que a nossa experiência permitiu. O critério seguido neste trabalho foi o mesmo que nos orientou nos anteriores, realizados com drogas semelhantes (Carvalho et al., 1962, p.6).

Outros exemplos são: "O emprego da trifluperazina em doenças mentais" (Carvalho et al., 1962), "Emprego do bromidato de alfa-amino glutamato de magnésio em psiquiatria infantil: contribuição clínica a partir de 21 casos" (Carvalho et al., 1963), "Efeitos colaterais das drogas psicotrópicas" (Bastos, 1963) e "Relato de autoexperiência com um psicodisléptico (Psilocibina) (Fortes et al., 1963), "Sobre um caso de desdobramento de personalidade analisado com auxílio de dietilamida do ácido lisérgico (LSD-25)" (Martins et al., 1964), "Emprego do neuleptil em terapêutica psiquiátrica - estudo clínico" (Silva et al., 1965) e "A tioridazina no tratamento das desordens mentais" (Bastos et al., 1965). O objetivo comum aos trabalhos é avaliar os efeitos dessas medicações na população escolhida.

Vale a pena comentar que a época permitiu a realização de trabalhos como o "Relato de autoexperiência com um psicodisléptico (Psilocibina)", de Albuquerque Fortes et al. (1963), em que os psiquiatras ingeriram a substância a fim de experimentar os efeitos produzidos. Também no artigo de Martins et al. (1964) que testou o LSD, buscou-se analisar a personalidade de uma paciente mediante experiência lisérgica. O Boletim mostra que, aparentemente, o LSD foi usado como um "soro da verdade", para mostrar que a paciente em questão estava desadaptada, segundo interpretação, por não cumprir com suas funções de mãe e esposa:

Aos poucos sua integração nos conteúdos mais traumatizantes do ambiente familiar foi se realizando através das vivências lisérgicas. Sua atitude modificou-se a favor de maior capacitação das responsabilidades de mulher e de mãe: voltou-se para o marido e para os filhos. Problemas sexuais vieram à superfície, pela primeira vez, admitiu ser sexualmente fria, pedindo ao médico solução para o problema (Martins et al., 1964, p.120). 
Em paralelo, outros métodos de tratamento ainda eram utilizados, como as terapias de choque: elétrico, cardizaólico e insulínico, como afirmaria o artigo de Waldeck d'Almeida (1966), em que tais terapêuticas são comparadas às drogas para tratamento de depressão (imipramina, amitriptilina, nortriptilina, desipramina e amimetilina), com as quais se buscava esquadrinhar as indicações terapêuticas segundo as características dos quadros clínicos.

\section{A presença da psicanálise, do psicodrama e da psicologia}

A década de 1960 era marcada pela forte presença da psicanálise no campo psi (Coimbra, 1995; Russo, 2002). Em 1962, com a oficialização da profissão de psicólogo, o mercado profissional psi passa a pressionar instituições psicanalíticas, denunciando os altos preços das formações nos institutos ligados à Associação Internacional de Psicanálise (IPA). Além disso, esse novo contingente de profissionais colabora com a chegada de novas práticas de psicoterapia, que gradativamente se institucionalizariam em São Paulo (Cepeda, Martim, 2010). Os seguintes textos demonstram a presença de psicanálise, psicologia analítica, psicologia, psicodrama e psicoterapia de grupo:

- 1962: "Comentários sobre a teoria dos complexos de Carl Gustav Jung" (Galvão Bueno); "The function of the psychoanalyst in a general hospital" (Samuel Safirstein);

- 1965: "Introdução ao estudo da psicossexologia" (Fernando Bastos);

- 1966: "As relações sociais na idade adulta", "Escolas psicológicas: análise histórica", "Fundamentos da escola fenomenológica", "Fundamentos da escola gestáltica", "Fundamentos da escola psicanalítica" e "Fundamentos das escolas analíticas dissidentes" (conferências); "Psicodinâmica no grupo" (Clóvis Martins);

- 1967: "Notas sobre a evolução de um grupo terapêutico" (Antônio Carlos Eva), "Psicoterapia: alcances y limitaciones" (Humberto Rosseli);

- 1968: "Atividade do setor de psiquiatria do grupo do departamento de psiquiatria da FMUSP" (Jorge Amaro et al.); "Contribuição ao estudo do observador em grupoterapia" (Jorge Amaro et al.);

- 1969: “O psicólogo clínico na equipe psiquiátrica" (José Arthur D’Incao);

- 1970: "Psicodrama na Clínica Psiquiátrica FMUSP" (Jorge Amaro e Alfredo Carlos Soeiro).

Em 1963, Clóvis Martins e Fernando Bastos publicam o "Estado atual de psicoterapia no Brasil", em que dizem:

Ao analisar problemas de psicoterapia preferimos colocar num mesmo nível postulados e princípios puramente médicos ao lado de perspectivas fornecidas pela antropologia cultural, para bem fundamentar nosso ponto de vista e transmitir uma visão ampla e objetiva do tema. Encarada a psicoterapia como uma forma de terapêutica sobre o psiquismo do homem, procuramos dividir as fontes de atuação psicoterápica atualmente existentes no país em dois grandes grupos: o primeiro deles, dentro dos moldes científicos clássicos, reúne os representantes da medicina oficial e concerne a psicoterapia de apoio, psicoterapia com objetivos educativos ou reeducativos, psicoterapia de objetivos reconstrutivos (psicanálise freudiana, dos dissidentes de Freud e a analítica existencial), hipnose e psicoterapia de grupo; no segundo grupo colocamos seitas religiosas, chamadas espiritualistas, que em função 
de suas características fundamentalmente mágico-primitivas exercem influência através da liturgia religiosa, procurando atingir, na sua marcha proselitista, o homem doente e o desajustado psíquico e que representam no plano sociocultural, papel de grande relevo ao atender de forma muitas vezes exclusiva, grande massa de doentes necessitados de assistência (Martins, Bastos, 1963, p.49).

Em seu conjunto são textos que revelam o interesse pela área, além da tentativa de hierarquização, com a subordinação dos saberes à lógica psiquiátrica. O afastamento da psiquiatria dessas áreas ocorria assim posteriormente aos anos 1970, justamente quando medicações e padronizações diagnósticas tornam-se possíveis (Dunker, 2014; Burkle, 2009).

No caso do psicodrama, que chegava a São Paulo em meados da década de 1960 por intermédio de Jaime Rojas-Bermudez, ${ }^{2}$ nota-se sua presença e desenvolvimento na FMUSP, com núcleo formado por Jorge Amaro. O Boletim informa:

Com isto em março de 1968, foi fundado o Setor de Psicodrama, adido ao Setor de Psicoterapia de Grupo. Atualmente conta com uma grande equipe de médicos e psicólogos interessados em psicodrama. Moreno é o pai do Psicodrama e Bermudez o seu herdeiro. Bermudez, líder na América do Sul em terapia psicodramática, é agora oficialmente recebido e credenciado em São Paulo (Amaro, Soeiro, 1969, p.177).

Esse núcleo contribui para o estabelecimento do psicodrama na cidade e tem importante papel no conhecido quinto Congresso Internacional de Psicodrama e no primeiro Congresso Internacional de Comunidades Terapêuticas, realizados no Museu de Arte de São Paulo, em 1970. Evento de suma importância, atraiu enorme público e marcou o posicionamento político de vários profissionais psi contra a ditadura militar (Motta, 2010). O psicodrama constituiu-se em uma alternativa importante para aqueles que encontravam dificuldades para serem admitidos na psicanálise e por seu trabalho com terapia em grupo (Cepeda, Martim, 2010).

A psicologia experimental também se fazia presente no hospital. Entretanto, diferente do que ocorria fora, em que a psicologia passava a desempenhar funções clínicas desde 1962, no hospital os psicólogos e psicólogas tinham funções mais determinadas, como mostra o artigo de José Arthur D’Incao (1969, p.4):

Basicamente, num grande hospital psiquiátrico, o psicólogo é aquele profissional que aplica testes de inteligência e personalidade, escreve relatórios dos resultados obtidos e o encaminha para outros setores. O que é feito, posteriormente, com o paciente, a orientação terapêutica a ser empregada, tudo isso, é considerado como não sendo de sua competência. Em situações mais felizes, o psicólogo pode colaborar com uma equipe de neurocirurgia. Na clínica particular, o psicólogo pode solucionar problemas de ajustamento (lei que regulamentou a profissão) e então, deixa de lado a formação mais experimental e deriva para teorias surgidas da observação clínica: a psicanálise, por exemplo, e suas modalidades.

O autor, professor de psicologia experimental na própria Universidade de São Paulo, explicita bem a posição do psicólogo no hospital, o que acompanha a literatura (Alarcão et al., 2016). Em 1969, no artigo de Lúcia Coelho, psicóloga, encontramos ainda mais destacadas essas evidências quando ela enumera as contribuições dos psicólogos que 
atuavam dentro dos hospitais psiquiátricos e afirma que haveria competição entre médicos e psicólogos pelo exercício da psicoterapia, dizendo que médicos se irritavam com psicólogos por considerarem que esses seriam filósofos (Coelho, 1969, p.190).

Concluindo esta seção, temos o trabalho de Carlos David Segre sobre comunidade terapêutica em 1970. Influenciado por Franco Basaglia, ele coordenou uma experiência de constituição de uma comunidade terapêutica dentro de uma enfermaria da clínica psiquiátrica. Segre menciona o encontro com Basaglia durante a visita deste à FMUSP em 1969. Experiência arrojada e desafiadora para a instituição, foi relatada pelo autor:

Quanto à causa do fracasso, além de fatores externos (a meu ver secundários em importância, no momento em que se verificou o fim da experiência) isto é, pressões administrativas, inveja por parte de outros setores do hospital, barreiras para certas resoluções na enfermaria, que dependiam da aprovação da administração, os fatores internos foram os mais importantes: a disputa motivada por rivalidade de chefia levou a conflitos insuperáveis e que não foram trabalhados construtivamente; a equipe médica conscientizou-se de que deveria trabalhar o tempo todo, mas isto se choca com a realidade externa; descrédito e rivalidade entre as várias categorias da equipe técnica levaram a autoacusações mútuas e por fim à suspensão da experiência como 'impossível' de se realizar na atual estrutura social e no modo de constituição do hospital. Cabe assinalar que, embora fracassada, a experiência foi útil como vivência e chama atenção o fato de que, embora num hospital fechado, se pôs em ação uma tentativa de contrato de internação, procurando não coagir a pessoa a se internar e ao mesmo tempo buscar com que ela se responsabilize por si mesma (Segre, 1970, p.185).

Tenório (2002) indica que iniciativas como a descrita no trecho acima constituem um dos eixos germinativos da futura reforma psiquiátrica. As comunidades terapêuticas representavam uma via de influência da psicanálise na psiquiatria e contribuíram para a concepção de saúde mental que viria em oposição à doença mental, símbolo do período em que a psiquiatria atuava como saber soberano no campo. A tentativa frustrada de Segre testemunha esse processo. Por um lado, o psiquiatra científico dedicava-se à formatação diagnóstica e ao teste de remédios e, por outro, usava diferentes saberes e práticas psi. Segre (1970, p.185) conclui com uma forte crítica à psiquiatria da época, algo inédito no Boletim:

Simplesmente internar o paciente em crise como fazemos hoje, entupindo-o de drogas ou fazendo-lhe ECT ou insulina é algo que além de muitas vezes pouco útil para o paciente, pode na melhor das hipóteses tranquilizar o médico. Precisamos procurar novas soluções.

\section{Considerações finais}

A Revista de Psiquiatria Clínica nasce em 1972 para substituir o Boletim. O texto que comemorou os quarenta anos de história da publicação não dá nenhuma pista sobre a existência do Boletim, construindo uma história que aparentemente começava a partir de 1972. Apenas um detalhe? São indagações como essa que incentivam algumas investigações no campo da história (Farge, 2011). O exame da década de textos contidos no Boletim indica que não se trata de mero detalhe, mas de uma decisão com consequências para a própria 
história da psiquiatria e do próprio campo psi. Contudo, esse fato precisa ser compreendido em conjunto com o que a própria história contida no Boletim apresenta: uma década em que a forma da psiquiatria divulgada em seus textos ainda não se configurava da forma padronizada e ajustada ao que se desenhava para o futuro.

O organicismo almejado, sempre propalado no discurso do psiquiatra cientista e médico, partilhava um espaço em consolidação. O Boletim demonstra a formação de uma racionalidade psiquiátrica que se anunciava mais formatada do que propriamente era. $\mathrm{O}$ psiquiatra cientista transitava entre outros saberes e prescrevia remédios baseando-se em grande empirismo, tratando e tentando conhecer ao mesmo tempo os efeitos da ação das novas medicações que chegavam triunfantemente.

A presença da psicoterapia e da psicanálise é amplamente constatada, como também a da psicologia analítica, do psicodrama e de trabalhos em psicoterapia de grupo. Não se deve esquecer que era um Serviço de Psicoterapia Médica (Alarcão, 2018), sendo necessário apontar o alinhamento ao organicismo e sua submissão à hierarquia da instituição. Isso significa dizer que tal presença continha, como visto, poucas críticas à prática psiquiátrica, produzindo poucos tensionamentos que viessem a averiguar com mais vigor o que era efetivamente produzido na instituição ou na psiquiatria como campo (Oliveira, 2005).

A principal função do Boletim era a de vocalizar e disseminar o desejo da psiquiatria: ser científica, médica e moderna. Não se abordam questões essencialmente conceituais sobre a psiquiatria, mas se divulgam informações e notícias, que ampliavam a audiência para o tipo de saber produzido na Clínica Psiquiátrica. O leitor do Boletim não encontraria uma psiquiatria autocrítica, mas um campo em consolidação e expansão, que se reassegurava para se fortalecer.

\section{NOTAS}

${ }^{1}$ Psiquiatra formado em 1944 pela Faculdade de Medicina da Universidade de São Paulo (FMUSP). É um dos responsáveis pela psiquiatria no Hospital do Servidor Público Estadual, ajuda na formação da Associação Brasileira de Psiquiatria (1966) e da Revista Brasileira de Psiquiatria (1967). Em 1970, entra em litígio pela disputa da vaga de professor-associado de psiquiatria com João Carvalhal Ribas (vencedor) na FMUSP.

${ }^{2}$ Médico colombiano nascido em 1926 e radicado na Argentina, onde atua como psiquiatra. Em 1959, presidiu o quarto Congresso Internacional de Psicodrama, em Buenos Aires. Em 1962, entra em contato com o fundador do psicodrama, Moreno, sendo nomeado, já em 1963, diretor do World Center for Psychodrama, Sociometry and Group Psychotherapy. Participa da formação dos primeiros psicodramatistas de São Paulo em fins de 1960 (Motta, 2010).

\section{REFERÊNCIAS}

ALARCÃO, Gustavo Gil. Na contracorrente? Resistências, adaptações e apropriações: a formação do serviço de psicoterapia do Instituto de Psiquiatria do Hospital das Clínicas da FMUSP, 1962-1965. Tese (Doutorado em Medicina) - Universidade de São Paulo, São Paulo, 2018.

ALARCÃO, Gustavo Gil; MOTA, André. O discurso de Antônio Carlos Pacheco e Silva sobre a psicanálise: São Paulo, 1926-1979. Saúde e Sociedade, v.28, n.2, p.272-285, 2019.
ALARCÃO, Gustavo Gil et al. Formation of psychoterapy service of FMUSP Psychiatry Institute: a brief historiographical approach. Revista de Medicina, v.95, número especial 2, p.93-100, 2016.

AMARO, Jorge Wohwey Ferreira. A história do Instituto de Psiquiatria do Hospital das Clínicas e do Departamento de Psiquiatria da FMUSP. Archives of Clinical Psychiatry, v.30, n.2, p.44-71, 2003. 
AMARO, Jorge Wohwey Ferreira; SOEIRO, Alfredo. Psicodrama na Clínica Psiquiátrica do Hospital das Clínicas. Boletim da Clínica Psiquiátrica, v.8, n.4, p.175-187, 1969.

BASTOS, Fernando de Oliveira. Discurso em sessão solene de posse como professor catedrático. Boletim da Clínica Psiquiátrica, v.7, n.4, p.174-178, 1968.

BASTOS, Fernando de Oliveira. Efeitos Colaterais das Drogas Psicotrópicas. Boletim da Clínica Psiquiátrica, v.2, n.6, p.174-187, 1963.

BASTOS, Fernando de Oliveira, et al. A tioridazina no tratamento das desordens mentais. Boletim da Clínica Psiquiátrica, v.4, n.4, p.211-228, 1965.

BOURDIEU, Pierre. Razões práticas: sobre a teoria da ação. Campinas: Papirus, 2011.

BURKLE, Taathy da Silva. Uma reflexão crítica sobre as edições do manual de diagnóstico e estatística das perturbações mentais: DSM. Dissertação (Mestrado em Saúde Coletiva) Universidade Federal do Rio de Janeiro, Rio de Janeiro, 2009.

CARVALHO, Henrique Marques et al. O emprego do bromidato de alfa-amino glutarato de magnésio em psiquiatria infantil: contribuição clínica a respeito de 21 casos. Boletim da Clínica Psiquiátrica, v.2, n.1, p.2-22, 1963.

CARVALHO, Henrique Marques et al. O emprego da trifluoperazina em doenças mentais: contribuição clínica a respeito de 24 casos. Boletim da Clínica Psiquiátrica, v.1, n.4, p.6-18, 1962.

CEPEDA, Norival Albergaria; MARTIM, Maria Aparecida F. Masp 1970: o psicodrama. São Paulo: Ágora, 2010.

COELHO, Lúcia. O psicólogo na equipe psiquiátrica. Boletim da Clínica Psiquiátrica, v.8, n.4, p.189-195, 1969.

COIMBRA, Cecília M. B. Guardiães da ordem: uma viagem pelas práticas psi no Brasil do milagre. Rio de Janeiro: Oficina do Autor, 1995.

COSTA, Jurandir Freire. História da psiquiatria no Brasil: um corte ideológico. Rio de Janeiro: Garamond, 2006.

COSTA, Jurandir Freire. Ordem médica e norma familiar. Rio de Janeiro: Graal, 2004.

D'ALMEIDA, Waldeck B. Tratamento das depressões: atualização terapêutica. Boletim da Clínica Psiquiátrica, v.5, n.3, p.133-143, 1966.

D'INCAO, José Arthur. A moderna psicologia experimental e algumas de suas implicações.
Boletim da Clínica Psiquiátrica, v.8, n.1, p.3-9, 1969.

DUNKER, Christian. Questões entre a psicanálise e o DSM. Jornal de Psicanálise, v.47, n.87, p.79-107, 2014.

FACCHINETTI, Cristiana; CUPELLO, Priscila; EVANGELISTA, Danielle Ferreira. "Arquivos Brasileiros de Psiquiatria, Neurologia e Ciências Afins": uma fonte com muita história. História, Ciências, Saúde - Manguinhos, v.17, supl.2, p.527$535,2010$.

FARGE, Arlete. Lugares para a história. Belo Horizonte: Autêntica, 2011.

FÁVERO, Maria de Lourdes de Albuquerque. A universidade no Brasil: das origens à Reforma Universitária de 1968. Educar em Revista, n.28, p.17-36, 2006.

FIGUEIREDO, Ana Cristina; TENÓRIO, Fernando. O diagnóstico em psiquiatria e psicanálise. Revista Latino-americana de Psicopatologia Fundamental, v.5, n.1, p.29-43, 2002.

FONSECA, Maria Rachel Fróes da. Fontes para a história das ciências da saúde no Brasil,1808-1930. História, Ciências, Saúde Manguinhos, v.9, supl., p.275-288, 2002.

FORTES, João Albuquerque et al. Relato de autoexperiências com um psicodisléptico (Psilocibina). Boletim da Clínica Psiquiátrica, v.2, n.6, p.188-194, 1963.

GAMA, Jairo Roberto de Almeida. A constituição do campo psiquiátrico: duas perspectivas antagônicas. História, Ciências, SaúdeManguinhos, v.19, n.1, p.139-155, 2012.

LUZ, Mariana Pires da et al. "Brazilian Journal of Psychiatry": a bibliometric study on the articles published from 1995 to 2004. Jornal Brasileiro de Psiquiatria, v.56, n.1, p.29-32, 2007.

MACHADO, Roberto et al. Danação da norma: a medicina social e constituição da psiquiatria no Brasil. Rio de Janeiro: Graal, 1978.

MARTINS, Clóvis. Nomenclatura internacional de doenças mentais. Boletim da Clínica Psiquiátrica, v.9, n.3, p.95-102, 1970.

MARTINS, Clóvis. Nota da redação. Boletim Bibliográfico da Clínica Psiquiátrica, v.2, n.2, p.44, 1963a.

MARTINS, Clóvis. Nota da redação. Boletim Bibliográfico da Clínica Psiquiátrica, v.2, n.3, p.100, 1963b.

MARTINS, Clóvis. Nota da redação. Boletim Bibliográfico da Clínica Psiquiátrica, v.1, n.2, p.1618,1962 a. 
MARTINS, Clóvis. Nota da redação. Boletim Bibliográfico da Clínica Psiquiátrica, v.1, n.1, p.1-2, 1962b.

MARTINS, Clóvis; BASTOS, Fernando de O. Estado atual da psicoterapia no Brasil: relatório apresentado no II Congresso Latino-Americano de Psiquiatria, México, 1962. Boletim da Clínica Psiquiátrica, v.2, n.2, p.49-53, 1963.

MARTINS, Clóvis et al. Sobre um caso de desdobramento de personalidade analisado com auxílio de dietilamida do ácido lisérgico. Boletim Bibliográfico da Clínica Psiquiátrica, v.3, n.3, p.110-121, 1964.

MOTA, André. A "Revista de Medicina": entre história e registros, 1916-1940. Revista de Medicina, v.91, p.5-12, 2012.

MOTTA, Julia M.C. 1970: o congresso que redefiniu o campo do psicodrama brasileiro. Revista Brasileira de Psicodrama, v.18, n.2, p.119128, 2010.

OLIVEIRA, Carmen Lúcia Montechi Valladares. História da psicanálise: São Paulo, 1920-1969. São Paulo: Escuta, 2005.

RUSSO, Jane F. O mundo psi no Brasil. Rio de Janeiro: Jorge Zahar, 2002.

RUSSO, Jane; VENANCIO, Ana Teresa.

Classificando as pessoas e suas perturbações: a "revolução terminológica" do DSM-III. Revista
Latino-americana de Psicopatologia Fundamental, v.9, n.3, p.460-483, 2006.

SEGRE, Carlos D. Comunidade terapêutica. Boletim da Clínica Psiquiátrica, v.9, n.4, p.181-185, 1970.

SILVA, Antônio Carlos Pacheco e. Sobre a necessidade da criação de um Hospital Psiquiátrico Municipal na cidade de São Paulo. Boletim da Clínica Psiquiátrica, v.9, n.1, p.17-23, 1970.

SILVA, Antônio Carlos Pacheco e. Contribuição ao estudo de uma classificação das doenças mentais. Boletim Bibliográfico da Clínica Psiquiátrica, v.1, n.4, p.9-13, 1962.

SILVA, Antônio Carlos Pacheco et al. Emprego do neuleptil em terapêutica psiquiátrica: estudo clínico. Boletim da Clínica Psiquiátrica, v.4, n.2, p.69-76, 1965.

SILVA, Públio Salles. O Centro de Neurocirurgia Funcional da Clínica Psiquiátrica. Boletim Bibliográfico da Clínica Psiquiátrica, v.1, n.5, p.8$15,1962$.

TENÓRIO, Fernando. A reforma psiquiátrica brasileira, da década de 1980 aos dias atuais: história e conceitos. História, Ciências, SaúdeManguinhos, v.9, n.1, p.25-59, 2002.

ZARETSKY, Eli. Segredos da alma: uma história sociocultural da psicanálise. São Paulo: Cultrix, 2006.

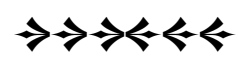

